\title{
Bi-Objective Multiple Criteria Data Envelopment Analysis combined with the Overall Equipment Effectiveness: An application in an automotive company
}

\author{
Aneirson Francisco da Silva*, Fernando Augusto Silva Marins, Patricia Miyuki Tamura, \\ Erica Ximenes Dias \\ São Paulo State University, Faculty of Engineering, Campus of Guaratinguetá, 12516-410, 333 Ariberto Pereira da Cunha Av., Guaratinguetá, SP, Brazil
}

\section{A R T I C L E I N F O}

\section{Article history:}

Received 18 January 2017

Received in revised form

24 April 2017

Accepted 24 April 2017

Available online 3 May 2017

\section{Keywords:}

Overall machinery effectiveness

Data envelopment analysis

Multiple criteria data envelopment analysis

BiO-MCDEA models

Overall equipment effectiveness

\begin{abstract}
A B S T R A C T
The mass production companies need to seek high efficiency in the use of equipment and human resources, as well as in the consumption of their inputs. One of the key methods to address these challenges is the adoption of Overall Equipment Effectiveness, derived from Total Productive Maintenance. This work aims to propose a new efficiency indicator, called Overall Machinery Effectiveness, to be applied in an automotive company in Brazil that adopted Overall Equipment Effectiveness indicator. The studied company made available production data from ten months, associated to two Press machines, generating twenty Decision Making Units for Data Envelopment Analysis and Bi-Objective Multiple Criteria Data Envelopment Analysis models application. As results, Press \#2 was identified as being the most critical because, among the first ten DMUs in the efficiency ranking, seven are associated to Press $\# 1$. The targets values recommended by the new indicator were considered feasible to be implemented by the company, thus validating in practice the new proposed procedure for the management of machines effectiveness. Moreover, the identification of the relevant variables (input and output) for the Press \#1, and Press \#2, allowed the decision maker to act in the best way to increase their efficiency.

( 2017 Elsevier Ltd. All rights reserved.
\end{abstract}

\section{Introduction}

According to Eswaramurthi and Mohanram (2013), mass production companies must have high efficiency in equipment use, human resources, and inputs in general. Aktin and Gergin (2011) commented that companies operating in today's challenging market conditions require an effective procurement process to gain competitive advantage. For Schöggl et al. (2017), in automotive industries, sustainable development is of particular importance, and they need to comply with environmental standards and meet societal requirements, but also maintain a competitive edge in a

Abbreviations: TPM, Total Productive Maintenance; OEE, Overall Equipment Effectiveness; DEA, Data Envelopment Analysis; DMUs, Decision Making Units; DEA-CCR, DEA model proposed by Charnes, Cooper and Rhodes; DEA-BCC, DEA model proposed by Banker, Charnes, and Cooper; MCDEA, Multiple Criteria DEA; BiO-MCDEA, Bi-Objective MCDEA; OME, Overall Machinery Effectiveness; SMED, Single-Minute Exchange of Die; WF, Workforce; MSA, Measurement Systems Analysis; VBA, Visual Basic for Application.

* Corresponding author.

E-mail address: aneirson@feg.unesp.br (A.F. da Silva). rapidly-changing business (Maxwell and van der Vorst, 2003; Zhu et al., 2007).

For Maclean and Lave (2003); Mayyas et al. (2012) and Jasinski et al. (2015), examples of strategies used by automotive company to mitigate social and environmental effects include investment in clean technologies, design for sustainability and creating value for local and global communities.

One of the main tools to be used in order to face these challenges is the Total Productive Maintenance System (TPM), that aims at adding business value to an organization by maintaining and improving the integrity of production and quality systems involving collaborators, processes, and machines (Eswaramurthi and Mohanram, 2013). The objective of TPM is to improve the Overall Equipment Effectiveness (OEE) of plant machine, which is considered the broadest set of performance measures to analyze the efficiency of a single manufacturing machine or an integrated system (Ferko and Znidarsic, 2007). For Nallusamy (2016), OEE of a machine plays a significant role in the present scenario, where right quality and right delivery at the right time are the major factors influencing a customer. 
According to the definition of Nakajima (1989), OEE is measured based on the six large losses, considering machine availability, performance and quality rates (Ahire and Relkar, 2012). It does not identify a specific reason why the machine is not as efficient as it should be, but it assists in categorizing areas in order to identify those that are in need of equipment improvement most (Eswaramurthi and Mohanram, 2013).

On the other hand, mathematical models have been developed to quantify performance, quality and flexibility and to justify investments in production systems (Liu, 2008); and in order to manage operational performance, different approaches can be used (Ferko and Znidarsic, 2007).

As pointed by Chen and Jia (2017) and Haghighi et al. (2016), there are two main methods on efficiency evaluation; the first one is stochastic frontier analysis method, which is a parametric approach, and other that is a nonparametric method, known as Data Envelopment Analysis (DEA). In practice, DEA has been regarded as an alternative multiple criteria tool for manufacturing technology assessment (Liu, 2008), and for evaluating performance and decision-making processes (Dotoli et al., 2015).

The DEA CCR model (Charnes et al., 1978), with constant return of scale, and DEA BCC model (Banker et al., 1984), with variable return of scale, can be used to evaluate relative efficiency of a set of homogeneous Decision Making Units (DMUs); moreover, these DEA models do not require a specific form of the production function and they are especially suitable for multi-input and multi-output scenarios (Cook et al., 2014; Ohsato and Takahashi, 2015).
It should be observed that, according to Banker et al. (1989), DEA (CCR and BCC) models may present problems to discriminate the efficient DMUs adequately if specific conditions are not met, named as DEA Golden Rules, with respect to a minimum amount of involved DMUs. In this sense, in order to avoid such a problem new multiple criteria DEA models have been proposed, such as the MCDEA - Multiple Criteria DEA (Li and Reeves, 1999), and the BiOMCDEA - Bi-Objective Multiple Criteria DEA (Ghasemi et al., 2014).

A citation report (see Table 1) was done with data from an important database (Web of Science) to characterize the up to date importance of the problem investigated here, as well as to identify the existing gaps (questions) in the theory, and whose solutions (answers) could be of great interest in everyday of companies.

Fig. 1 shows the results of publications and citations obtained by searching the Web of Science by using the keyword "Data Envelopment Analysis", it is noticed that, in the period of 1998-2017, there was more than 9900 publications, and more than 121,900 citations. These results demonstrate that such tool have been widely adopted in solving several problems in different contexts.

Fig. 2 shows the results of publications and citations obtained by searching the Web of Science by using the keywords "Overall Equipment Effectiveness and OEE". It is noticed that, in the period from 1998 to 2017, more than 160 publications, and more than 550 citations, that is, OEE is a technique widely used.

Figs. 1 and 2 show that the OEE and the DEA have been widely applied, but individually. In fact, combining the keywords "Overall Equipment Effectiveness, OEE, and Data Envelopment Analysis"

Table 1

Citation Report from Web of Science database for Period 1998-2017.

\begin{tabular}{|c|c|c|}
\hline Keywords Combinations & Number of Publications & Citations \\
\hline “Data Envelopment Analysis" & 9965 & 121,947 \\
\hline “Overall Equipment Effectiveness and OEE” & 164 & 599 \\
\hline "Data Envelopment Analysis and Overall Equipment Effectiveness" & 4 & 48 \\
\hline “Overall Equipment Effectiveness and Automotive Industry" & 6 & 48 \\
\hline “Multiple Criteria Data Envelopment Analysis and MCDEA". & 10 & 254 \\
\hline “Total Productive Maintenance and Overall Equipment Effectiveness” & 64 & 321 \\
\hline “Total Productive Maintenance and Data Envelopment Analysis” & 3 & 23 \\
\hline “Overall Equipment Effectiveness; Improving efficiency of machine and Efficiency of productive process” & 4 & 0 \\
\hline "Improving efficiency of machine; Data Envelopment Analysis and machine and Efficiency of productive process" & 0 & 0 \\
\hline “Multiple Criteria Data Envelopment Analysis and Overall Equipment Effectiveness" & 0 & 0 \\
\hline "Bi-Objective Multiple Criteria Data Envelopment Analysis and Overall Equipment Effectiveness" & 0 & 0 \\
\hline
\end{tabular}

Source: Web of Science.
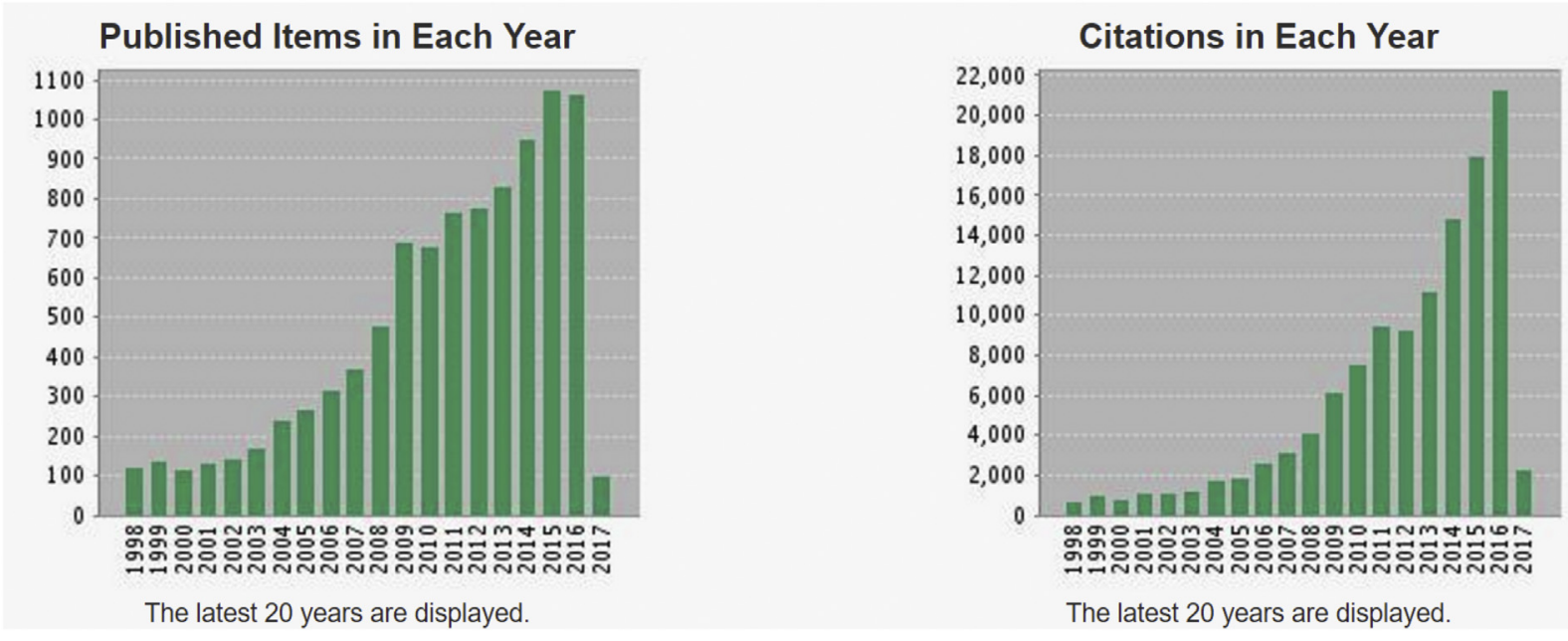

Fig. 1. Publications and citations by searching the keyword "Data Envelopment Analysis". Source: Web of Science. 

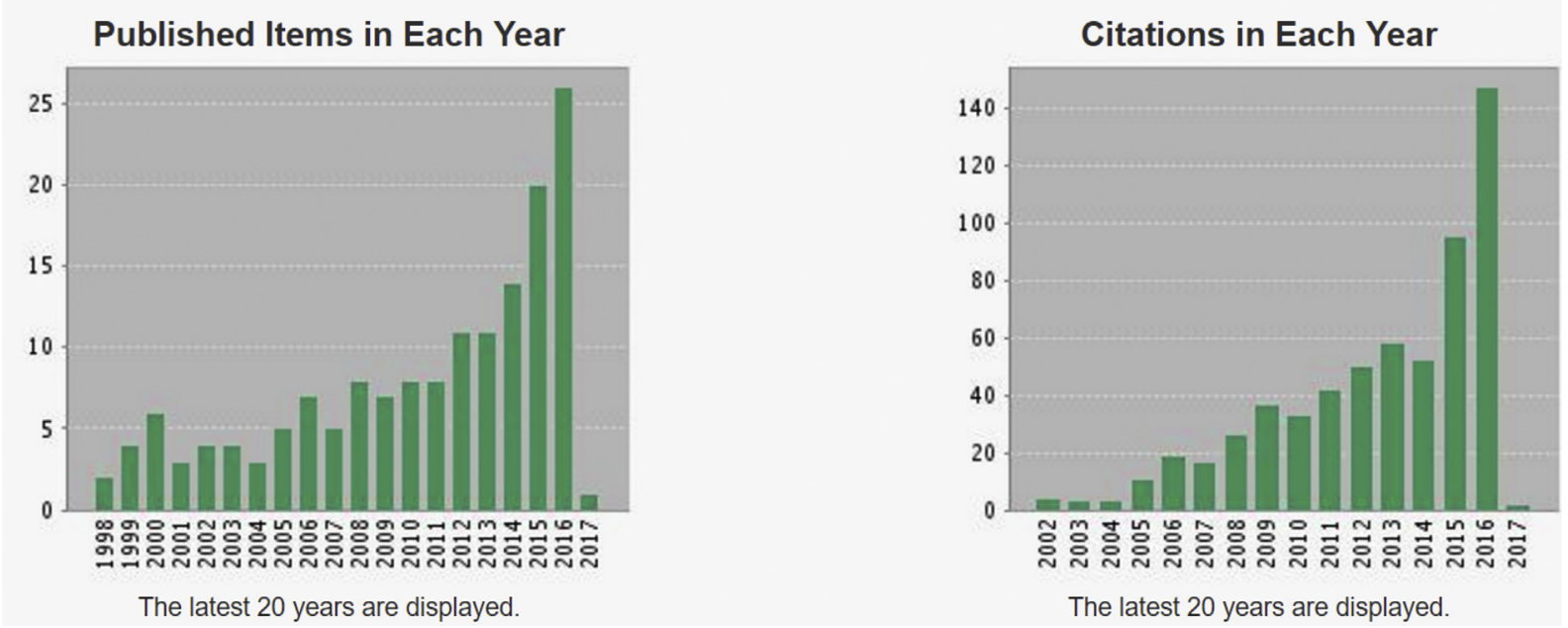

Fig. 2. Publications and citations by searching the keywords "Overall Equipment Effectiveness and OEE". Source: Web of Science.

found that, in the period 1998-2017, there were only four published works in the database consulted, and the number of citations (forty-eight) is not expressive, as shown in Fig. 3. Moreover, note that there are no publications since 2012, but there is an increasing number of citations, which indicates there is an interest in the joint application of both techniques.

As a final result, in Table 1 is the complete Citations Report, for the period 1998-2017, with the combinations of several key words correlated to the theme of this article.

As the complete Citation Report in Table 1 pointed out, there is much interest in improving the performance of machines and production processes, in particular with the use of innovative procedures, and there are some research gaps that have led to the development of this article. As an example, no publication was found that addresses the joint use of MCDEA and BiO-MCDEA with OEE, which identifies the existence of a research gap, which characterizes one of the contributions of this work.

In this context of interest in measuring the efficiency of machines, or productive processes, taking into consideration the cost of investments for such, one can express the research questions that motivated this work as being:
- How to identify where to make the modifications to improve the performance of machines, or processes, so that the investments are properly directed and have effectiveness in their results?

- How to identify at what level (target values) the modifications must be made to improve the performance of machines, or processes?

Looking for answers to the research questions that guided this article, the overall aim of this work was to propose a new indicator called as OME - Overall Machinery Effectiveness to rank machines (DMUs) in terms of their efficiency, in addition to identifying targets to make them more efficient, and to identify alternative production plans for improving global performance in the studied industry herein. For developing this new indicator, we decided to test two possibilities: to combine OEE with DEA model and to combine OEE with BiO-MCDEA model. Both proposed indicators were tested in a real industrial problem related to how to evaluate the efficiency of heavy mechanical presses (DMUs - Decision Making Units for DEA modelling) from an automotive industry in Brazil.

The research classification used in this study can be classified as being an Applied and Quantitative Research, with Normative and Empirical goals, because it is primarily interested in developing

\section{Published Items in Each Year}

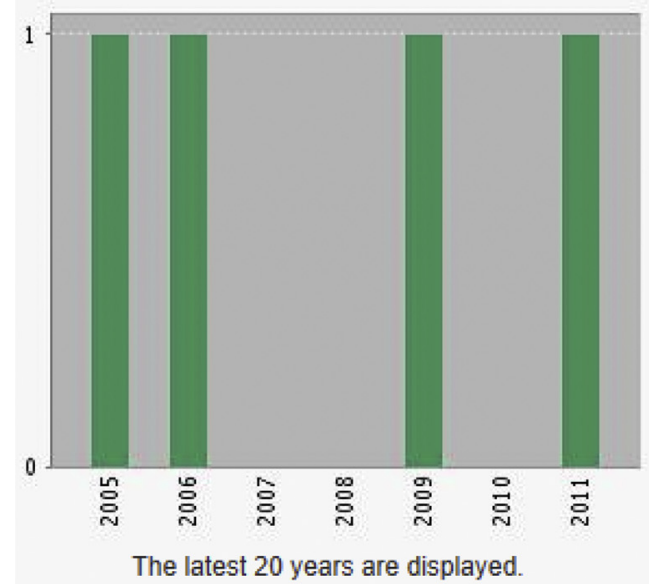

\section{Citations in Each Year}

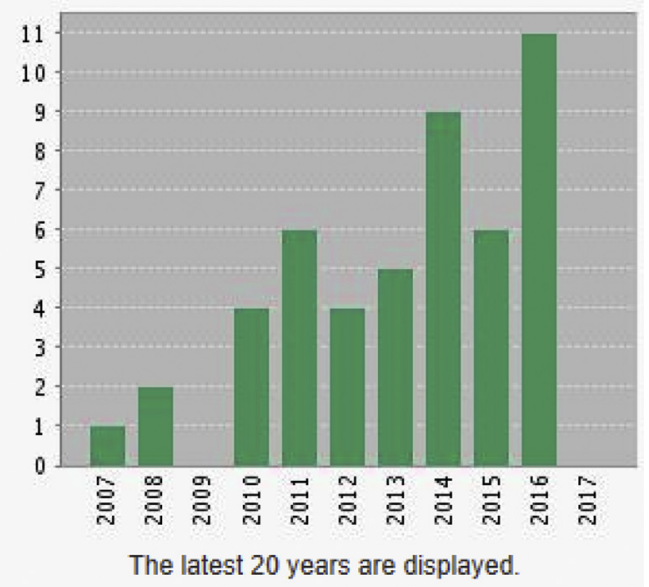

Fig. 3. Publications and citations by searching the keywords "Data Envelopment Analysis and Overall Equipment Effectiveness". Source: Web of Science. 
policies, strategies and actions to improve a current situation. The adopted research method was modelling and simulation (Bertrand and Fransoo, 2002).

This article was organized into four other sections, beyond this introduction. Section 2 presents problem and research phases descriptions; in Section 3 are main OEE concepts, and formulation of DEA and MCDEA models; Section 4 gives optimization and results analysis; and finally, Section 5 presents conclusions, and recommendations for further research, followed by the bibliographic references.

\section{Problem and research phases descriptions}

In Fig. 4 there is a flow chart illustrating the steps developed in this research, which are explained in the sequence.

This study was conducted in an automotive industry that manufactures structural components for cars and trucks in Paraiba Valley - São Paulo State, Brazil. It was focused on two mechanical presses with the capacity of $3000 \mathrm{t}$, machine setup time of $1 \mathrm{~h}$ and

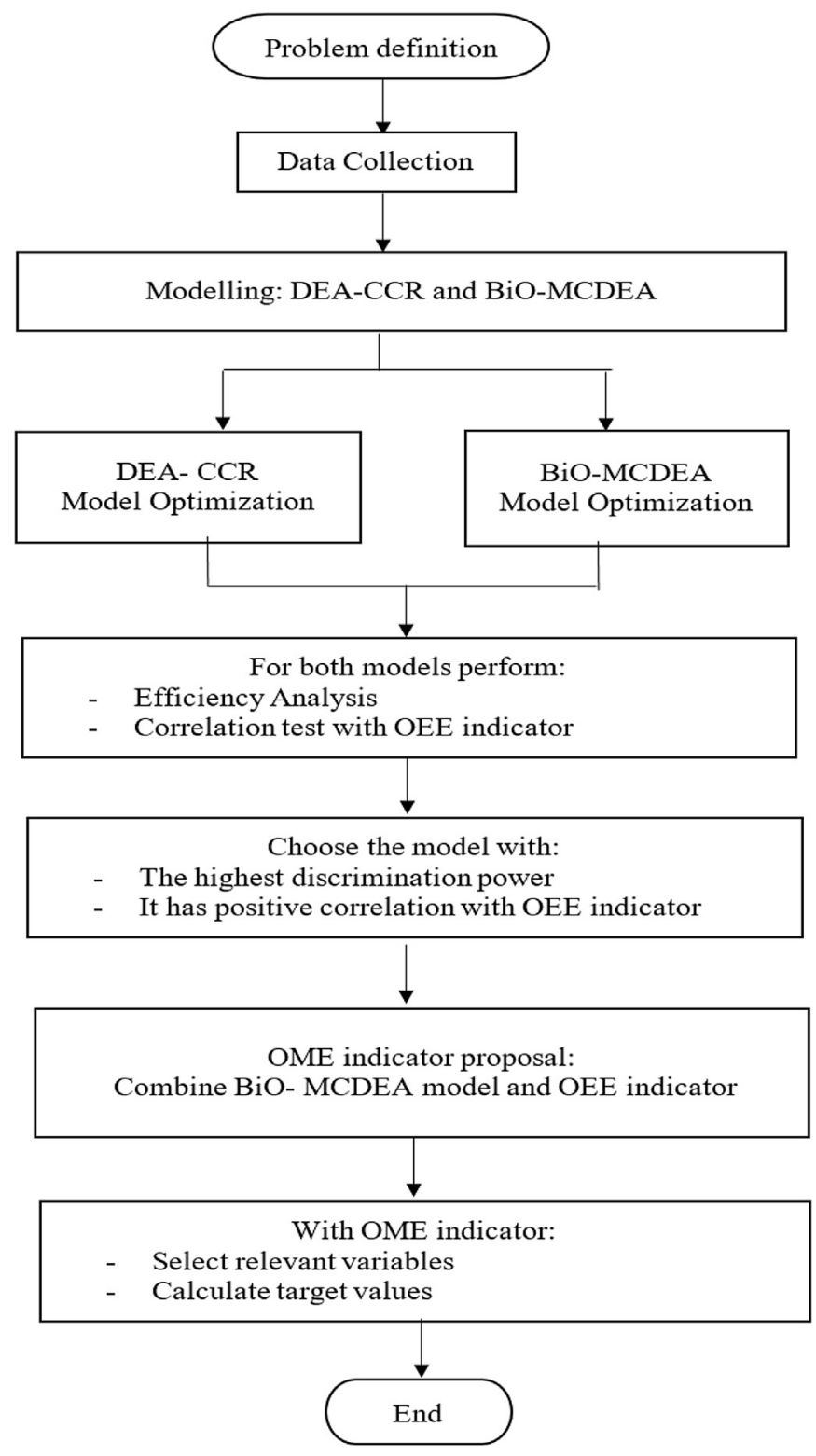

Fig. 4. Research phases. external setup time of $4 \mathrm{~h}$. In order to formulate the problem to be treated in this research, we have contacted decisions makers of the chosen company, and we verified that among the objectives of it were the interest in identifying how to properly measure the efficiency of the presses, how to identify which parameters and production characteristics would be likely to be modified to improve the performance of these machines, and what would be the reference values to make such changes, looking for making good use of the resources available in the company for this purpose.

Table 2 shows the database provided by the company on two mechanical presses for the period from January to October 2015, as well as associated OEE values calculated by the company.

For DEA modelling, we considered twenty Decision Making Units (DMUs) associated to the monthly production of two mechanical presses from January to October 2015. Thus, the ten first DMUs correspond to Press \#1, in the period of January to October 2015, while the following ten DMUs correspond to Press \#2 within the same period of 10 months. Moreover, after consulting decision maker of the studied company, we considered:

Relevant inputs

- Total available time - represents the time, in hours, available for parts production.

- Setup downtime - represents the time, in hours, spent on setup.

- Other downtimes - represent the time, in hours, spent on other downtimes, as the operators' lunch break.

- Personnel staff - represents the amount of workforce (WF) required to operate the presses line.

- Scrap generated along the process (undesirable output) - represents the amount of scrap generated during the presses operation.

\section{Relevant output}

- Production volume - represents the volume produced during the considered period.

Modeling and optimization of DEA-CCR (see expressions (9)-(13)) and BiO-MCDEA see expressions (22)-(28)) models were performed via VBA and Excel $^{\circledR}$ programming (see files Supplementary Data DEA-CCR - Appendix A, and Supplementary Data BiO-MCDEA - Appendix B) by using the Simplex algorithm (Hillier and Lieberman, 2010). In these quantitative method applications, an intel core i7, GHZ processor 2.8 with 16 GB RAM and operational system iOS computer has been used, and computational times for the optimization of the models was about ten seconds.

The optimization results for both DEA-CCR and BiO-MCDEA models were compared with respect to their discrimination power. Additionally, it was analyzed the existing non-parametric correlations between the OEE values adopted by the company and efficiency values obtained by DEA-CCR and BiO-MCDEA models. From these statistical tests, it was verified that the BiOMCDEA model was better than DEA-CCR model, and the OME indicator was proposed (see Section 4), a new ranking for DMUs was created, relevant variables were identified, and targets were established for non-efficient DMUs.

\section{Background on OEE, DEA and MCDEA}

In this section are presented concepts of OEE, and DEA, MCDEA and BiO-MCDEA models.

\subsection{OEE concepts}

Gupta and Vardhan (2016) investigated how the use of TPM led 
Table 2

Database of the analyzed company related to the performance of two mechanical presses - Period from January to October 2015.

\begin{tabular}{|c|c|c|c|c|c|c|c|c|}
\hline \multirow[t]{2}{*}{ PRESS } & \multirow[t]{2}{*}{ DMU } & \multicolumn{5}{|l|}{ Original Input Values } & \multirow{2}{*}{$\frac{\text { Original Output Value }}{u_{1} \text { (Volume) [unit] }}$} & \multirow{2}{*}{$\begin{array}{l}\text { OEE values calculated } \\
\text { by the company [\%] }\end{array}$} \\
\hline & & $x_{1}$ (Total hours) $[\mathrm{h}]$ & $x_{2}$ (Other downtimes) $[\mathrm{h}]$ & $x_{3}$ (Setup hours) $[\mathrm{h}]$ & $x_{4}(\mathrm{WF})$ [unit] & $x_{5}$ (Scrap) [unit] & & \\
\hline \multirow[t]{10}{*}{ \#1 } & 1 & 334.8 & 175.4 & 51.3 & 36 & 44 & 10,498 & 39.40 \\
\hline & 2 & 256.1 & 103.6 & 50.1 & 24 & 36 & 10,466 & 46.30 \\
\hline & 3 & 359.1 & 138.1 & 64 & 36 & 69 & 16,843 & 48.90 \\
\hline & 4 & 318.3 & 139.1 & 60.7 & 30 & 156 & 13,918 & 40.70 \\
\hline & 5 & 348.9 & 131.2 & 64.3 & 30 & 211 & 17,365 & 52.50 \\
\hline & 6 & 296.2 & 146.5 & 47.4 & 24 & 163 & 9808 & 47.20 \\
\hline & 7 & 273.6 & 128.4 & 43 & 24 & 100 & 10,752 & 50.50 \\
\hline & 8 & 324.9 & 159.3 & 53.5 & 27 & 154 & 12,239 & 44.00 \\
\hline & 9 & 315.7 & 145.5 & 55.6 & 27 & 75 & 11,366 & 47.10 \\
\hline & 10 & 318.1 & 165.3 & 55.5 & 27 & 58 & 9907 & 40.50 \\
\hline \multirow[t]{10}{*}{ \#2 } & 11 & 338.8 & 138.4 & 48.9 & 36 & 66 & 15,669 & 49.30 \\
\hline & 12 & 234.8 & 123.6 & 33.9 & 24 & 27 & 7829 & 39.00 \\
\hline & 13 & 395.5 & 170.5 & 57.9 & 36 & 73 & 17,773 & 44.20 \\
\hline & 14 & 136.9 & 58.7 & 26.2 & 26 & 84 & 7448 & 44.30 \\
\hline & 15 & 182.8 & 97.7 & 25.5 & 16 & 79 & 6497 & 54.00 \\
\hline & 16 & 218.4 & 154.9 & 27.5 & 16 & 72 & 4311 & 37.70 \\
\hline & 17 & 154.8 & 113.6 & 18.6 & 16 & 21 & 2284 & 41.30 \\
\hline & 18 & 197.3 & 122.7 & 21.3 & 16 & 73 & 5803 & 47.90 \\
\hline & 19 & 229 & 168.6 & 17.7 & 16 & 30 & 4449 & 43.00 \\
\hline & 20 & 147.3 & 95.8 & 17.6 & 16 & 18 & 2842 & 35.30 \\
\hline
\end{tabular}

to an increase in sales volume, improved machine OEE results, plant productivity, and total cost of production. OEE is a quantitative metric that has been used in production systems to control and monitor the equipment productivity, which also serves as a process and performance improvement indicator (Tsarouhas, 2013). In this way, an OEE of $85 \%$ is considered as worldwide performance standard (Blanchard, 1997).

The OEE can be calculated by using three indicators, Availability, Performance and Quality (Nakajima, 1989; Wudhikarn, 2012):

- Availability means the machine operating time, given that downtime comprises the time during which there are equipment failure, setups and adjustment requirements, which can be calculated by (1),

Availability $=($ Scheduled time - Downtime $) /($ Scheduled time $)$

- Performance compares the quantity produced with what was supposed to be produced as a function of equipment operating time, which can be calculated by (2),

Performance $=($ Quantity produced - Cycle time $) /$ Operating time

- Quality means the number of good products that are produced as a function of the total number of items, which can be calculated by (3),

\subsection{Data Envelopment Analysis and multiple criteria Data Envelopment Analysis}

Charnes et al. (1978) developed the DEA model, given by (4)-(8), with DMUs $\left(\mathrm{DMU}_{j} ; j=\{1,2, \ldots, n\}\right)$, which use resources or inputs $\left(x_{i} ; i=\{1,2, \ldots, m\}\right)$ and generate products or outputs $\left(y_{r}\right.$; $r=\{1,2, \ldots, s\})$ :

$\operatorname{Max} w_{0}=\sum_{r=1}^{s} u_{r} y_{r 0} / \sum_{i=1}^{m} v_{i} x_{i 0}$

subject to:

$\sum_{r=1}^{s} u_{r} y_{r 0} / \sum_{i=1}^{m} v_{i} x_{i 0}=1$

$\sum_{r=1}^{s} u_{r} y_{r j}-\sum_{i=1}^{m} v_{i} x_{i j} \leq 0, \quad j=1,2, \ldots, n$

$u_{r} \geq 0, r=1,2, \ldots, s$

$v_{i} \geq 0, \quad i=1,2, \ldots, m$

where $w_{0}$ is the efficiency value under analysis $\left(\mathrm{DMU}_{0}\right), y_{\mathrm{r} 0}$ and $x_{i 0}$ are the values of the $r$-th output and $i$-th input for $\mathrm{DMU}_{0}$, respectively, $y_{r j}$ is the value of the $r$-th output for the $j$-th DMU, $x_{i j}$ is the value of the $i$-th input for the $j$-th DMU, $u_{r}$ is the decision variable (weight) associated with the $r$-th output, and $v_{i}$ is the decision variable (weight) associated with the $i$-th input.

Quality $=($ Production volume - Defective quantity $) /$ Production volume

Although OEE appears to be a fairly clear indicator of performance measurement, it does require scope expansion or modification to fit the needs of different industries.
DEA models can be input-oriented - with the purpose of reducing the amount of used resources and keeping the obtained results constant, or output-oriented - seeking to increase the obtained results values and keeping the amount of used resources constant. 
In (9)-(14), it is formulated an input-oriented primal model, also known as the multiplier model or the DEA-CCR model, with constant return to scale:

$\operatorname{Max} w_{0}=\sum_{r=1}^{s} u_{r} y_{r 0}$

subject to:

$\sum_{i=1}^{m} v_{i} x_{i 0}=1$

$\sum_{r=1}^{s} u_{r} y_{r j}-\sum_{i=1}^{m} v_{i} x_{i j} \leq 0, j=1,2, \ldots, n$

$u_{r} \geq 0, r=1,2, \ldots, s$

$v_{i} \geq 0, \quad i=1,2, \ldots, m$

From the DEA-CCR model, Banker et al. (1984) proposed the DEA-BCC model, with variable return to scale, with the addition of a free variable $c_{0}$ to the objective function (9) and to the constraint (11).

In fact, there are two problems that can arise from using the DEA, according to Li and Reeves (1999): weak discriminating power which occurs when many DMUs are identified as efficient and unrealistic weight distribution that refers to a situation in which DMUs can be efficient, but present high values of weights for a single output, or low values of weights for a single input.

In order to avoid such problems, Li and Reeves (1999) have proposed the Multiple Criteria DEA (MCDEA) model, in which each efficiency criterion is an independent objective function, and it is formulated by (14)-(21):

Min $d_{0}\left(\operatorname{ormaxh}_{0}=\sum_{r=1}^{s} u_{r} y_{r 0}\right)$

$\operatorname{Min} \sum_{j=1}^{n} d_{j}$

Min $M$

subject to:

$\sum_{i=1}^{m} v_{i} x_{i 0}=1$

$\sum_{r=1}^{s} u_{r} y_{r j}-\sum_{i=1}^{m} v_{i} x_{i j}+d_{j}=0, \quad j=1,2, \ldots, n$

$M-d_{j} \geq 0, j=1, \ldots, n$

$u_{r}, v_{i} \geq 0, \quad r=1, \ldots, s ; i=1, \ldots, m$

$d_{j} \geq 0, \quad j=1, \ldots, n$

where $d_{0}$ measures efficiency of analyzed $\mathrm{DMU}_{0}, d_{j}$ is the inefficiency of DMU $j$, and $M$ is the highest inefficiency value for all DMUs.

In the MCDEA model (14)-(21), the three objectives are analyzed individually, with no order of preference. Efficiency gains are defined according to minimum and maximum criteria, which are more constrained than those defined by the classic DEA, and these generally identify fewer efficient DMUs (Ramón and Cristóbal, 2011). Thus, the MCDEA model does not aim at obtaining a great solution, but to find Pareto-optimal solutions, in which the final decision is made by the analyst.

On the other hand, Ghasemi et al. (2014) proposed the BiObjective Weighted DEA model (BiO-MCDEA) which seeks to meet two objectives simultaneously by considering a given weighting, according to (22)-(28):

$\operatorname{Min} h=\left(w_{2} M+w_{3} \sum_{j=1}^{n} d_{j}\right)$

subject to:

$\sum_{i=1}^{m} v_{i} x_{i 0}=1$

$\sum_{r=1}^{s} u_{r} y_{r j}-\sum_{i=1}^{m} v_{i} x_{i j}+d_{j}=0, j=1,2, \ldots, n$

$M-d_{j} \geq 0, j=1,2, \ldots, n$

$u_{r} \geq \varepsilon, \quad r=1,2, \ldots, s$

$v_{i} \geq \varepsilon, \quad i=1,2, \ldots, m$

$d_{j} \geq 0, j=1,2, \ldots, n$

The next section presents results of models optimization, as well as statistical tests conducted, OME proposition, a new ranking of the DMUs according to the OME and an identification of targets for inefficient DMUs.

\section{Optimization and results analysis}

Two optimizations were performed with DEA-CCR (input-oriented), and BiO- MCDEA CCR models, in order to find out DMUs efficiency ranking. It is worth mentioning that we took into account the value of $\varepsilon=0$ in (26)-(27). Table 3 shows these optimization results.

Table 3

Results of Efficiency Analysis by DEA-CCR and BiO-MCDEA models, for each DMU.

\begin{tabular}{lll}
\hline DMU & DEA CCR Model [\%] & BIO-MCDEA CCR Model [\%] \\
\hline 1 & 86.46 & 65.82 \\
2 & 100.00 & 78.31 \\
3 & 100.00 & 93.04 \\
4 & 88.94 & 84.83 \\
5 & 100.00 & 100.00 \\
6 & 74.03 & 69.00 \\
7 & 85.68 & 84.10 \\
8 & 81.96 & 79.11 \\
9 & 83.12 & 74.13 \\
10 & 74.02 & 64.53 \\
11 & 100.00 & 100.00 \\
12 & 100.00 & 72.75 \\
13 & 100.00 & 100.00 \\
14 & 100.00 & 55.71 \\
15 & 82.82 & 76.08 \\
16 & 52.70 & 44.78 \\
17 & 43.03 & 32.14 \\
18 & 85.02 & 66.11 \\
19 & 78.44 & 43.12 \\
20 & 60.26 & 40.52 \\
\hline
\end{tabular}


Table 4

Efficiency ranking by OME indicator, for all DMUs.

\begin{tabular}{ll}
\hline DMU & OME (BiO-MCDEA \& OEE) [\%] \\
\hline $\mathbf{5}$ & 72.46 \\
11 & 70.21 \\
$\mathbf{3}$ & 67.45 \\
13 & 66.48 \\
$\mathbf{7}$ & 65.17 \\
15 & 64.10 \\
$\mathbf{2}$ & 60.21 \\
$\mathbf{9}$ & 59.09 \\
$\mathbf{8}$ & 59.00 \\
$\mathbf{4}$ & 58.76 \\
6 & 57.07 \\
18 & 56.27 \\
12 & 53.27 \\
10 & 51.12 \\
1 & 50.92 \\
14 & 49.68 \\
19 & 43.06 \\
16 & 41.09 \\
20 & 37.82 \\
17 & 36.43 \\
\hline
\end{tabular}

- While the DEA-CCR model renders an amount of seven efficient DMUs, the BiO-MCDEA model only considers three efficient DMUs.

- The three DMUs that were considered efficient by the BiOMCDEA model are also efficient through the DEA-CCR model.

- Finally, by making an overall comparison, the values found by the BiO-MCDEA model are lower than those obtained by the DEA-CCR model, i.e. there is greater discrimination.

In order to identify whether there was some correlation between the results (Table 3) of the DEA-CCR and the BiO-MCDEA models with the OEE results (Table 2) of the presses during the 10 studied months, Spearman's rank correlation coefficient test was used. For such a purpose, Spearman's Correlation Coefficient values $\left(r_{s}\right)$ were calculated for the OEE \& DEA-CCR and OEE \& BiO-MCDEA combinations.

Spearman's coefficient is a statistical non-parametric correlation test that can take values in the range of $(-1,1)$, which either means there is a strong positive $\left(r_{s}\right.$ close to +1$)$ or negative $\left(r_{s}\right.$ close to -1 ) correlation. Data in Table 3 and expression (29) were used for the calculations:

$$
r_{s}=1-\frac{6 \sum \Delta_{i}^{2}}{\left(n^{3}-n\right)}
$$

where $n$ is the number of DMUs and, in this case, $\Delta_{i}$ are the values of differences between the efficiencies of each DMU resulting from each model (DEA CCR - column 2 and BiO-MCDEA - column 3, Table 3 ) and the respective OEE value (column 4, Table 2).

Once Spearman's correlation coefficient values were calculated, it was found that:

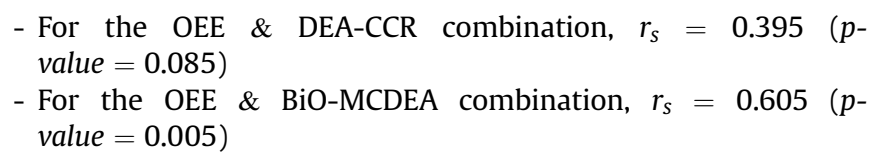

It can be observed that, at a statistical significance of $5 \%$, there is no correlation between the OEE values with the values resulting from using DEA-CCR model; however, the results generated by the BiO-MCDEA model are positively and statistically correlated with the OEE values.

Based on these results, a new Overall Machinery Effectiveness (OME) was additionally proposed to the company, which combines, by geometric mean, the BiO-MCDEA model efficiency values and the OEE values, as depicted in Table 4.

As the BiO-MCDEA model allows greater discrimination between the DMUs, it affects the OME and allows better prioritization of DMUs because identical values were not found, which could arouse doubts about choosing the DMU to be the investment focus so as to improve its efficiency.

In Table 4, one can verify that Press \#2 is the most critical because, among the first ten DMUs (highlighted in bold letters in Table 4) in the efficiency ranking, seven are associated to Press \#1. Thereby, it should be the object of further studies and possible investments.

Moving forward with the results analysis, targets were set out for reducing input and increasing output in order to make inefficient DMU's efficient based respectively on multiplying input values and dividing output values in Table 2 by the associated OME value.

Table 5

Weights for decision variables $v_{i}$ and $u_{r}$.

\begin{tabular}{|c|c|c|c|c|c|c|}
\hline \multirow[t]{2}{*}{ DMU } & \multicolumn{6}{|l|}{ Weights } \\
\hline & $v_{1}$ (Total hours) & $v_{2}$ (other downtimes) & $v_{3}$ (Setup hours) & $v_{4}(\mathrm{WF})$ & $v_{5}$ (Scrap) & $u_{1}$ (Volume) \\
\hline 1 & 0.0009 & - & 0.0089 & 0.0066 & - & 0.0001 \\
\hline 2 & 0.0011 & - & 0.0106 & 0.0079 & - & 0.0001 \\
\hline 3 & 0.0008 & - & 0.0078 & 0.0058 & - & 0.0001 \\
\hline 4 & 0.0009 & - & 0.0086 & 0.0064 & - & 0.0001 \\
\hline 5 & 0.0015 & - & 0.0037 & 0.0052 & 0.0004 & 0.0001 \\
\hline 6 & 0.0021 & - & 0.0025 & 0.0059 & 0.0007 & 0.0001 \\
\hline 7 & 0.0024 & - & 0.0027 & 0.0066 & 0.0007 & 0.0001 \\
\hline 8 & 0.0020 & - & 0.0023 & 0.0055 & 0.0006 & 0.0001 \\
\hline 9 & 0.0010 & - & 0.0092 & 0.0069 & - & 0.0001 \\
\hline 10 & 0.0010 & - & 0.0092 & 0.0069 & - & 0.0001 \\
\hline 11 & 0.0017 & - & 0.0041 & 0.0058 & 0.0004 & 0.0001 \\
\hline 12 & 0.0014 & - & 0.0132 & 0.0098 & - & 0.0001 \\
\hline 13 & 0.0015 & - & 0.0037 & 0.0051 & 0.0004 & 0.0001 \\
\hline 14 & - & - & - & 0.0344 & 0.0013 & 0.0001 \\
\hline 15 & 0.0036 & - & 0.0041 & 0.0099 & 0.0011 & 0.0001 \\
\hline 16 & 0.0032 & - & 0.0036 & 0.0088 & 0.0010 & 0.0001 \\
\hline 17 & 0.0037 & - & 0.0019 & 0.0219 & 0.0017 & 0.0001 \\
\hline 18 & 0.0035 & - & 0.0040 & 0.0096 & 0.0011 & 0.0001 \\
\hline 19 & 0.0040 & - & - & 0.0043 & 0.0008 & 0.0001 \\
\hline 20 & 0.0034 & - & - & 0.0287 & 0.0020 & 0.0001 \\
\hline
\end{tabular}


Table 6

Target values calculated by OME indicator.

\begin{tabular}{lllllll}
\hline \multirow{2}{*}{ DMU } & \multicolumn{7}{l}{ Target Values - OME Indicator } & & \\
\cline { 2 - 7 } & $x_{1}$ & $x_{2}$ & $x_{3}$ & $x_{4}$ & $x_{5}$ & $y_{1}$ \\
\hline 1 & 170.49 & - & 26.12 & 18.33 & - & $20,615.13$ \\
2 & 154.21 & - & 30.17 & 14.45 & - & $17,381.54$ \\
3 & 242.22 & - & 43.17 & 24.28 & - & $24,970.78$ \\
4 & 187.03 & - & 35.67 & 17.63 & - & $23,687.06$ \\
5 & 252.80 & - & 46.59 & 21.74 & 152.88 & $23,965.98$ \\
6 & 169.03 & - & 27.05 & 13.70 & 93.02 & $17,186.89$ \\
7 & 178.30 & - & 28.02 & 15.64 & 65.17 & $16,498.64$ \\
8 & 191.69 & - & 31.56 & 15.93 & 90.86 & $20,744.32$ \\
9 & 186.55 & - & 32.85 & 15.95 & - & $19,235.04$ \\
10 & 162.62 & - & 28.37 & 13.80 & - & $19,379.40$ \\
11 & 237.88 & - & 34.33 & 25.28 & 46.34 & $22,316.08$ \\
12 & 125.07 & - & 18.06 & 12.78 & - & $14,697.49$ \\
13 & 262.94 & - & 38.49 & 23.93 & 48.53 & $26,733.12$ \\
14 & - & - & - & 12.92 & 41.73 & $14,991.74$ \\
15 & 117.17 & - & 16.34 & 10.26 & 50.64 & $10,136.45$ \\
16 & 89.74 & - & 11.30 & 6.57 & 29.58 & $10,491.82$ \\
17 & 56.40 & - & 6.78 & 5.83 & 7.65 & 6268.72 \\
18 & 111.03 & - & 11.99 & 9.00 & 41.08 & $10,311.92$ \\
19 & 98.61 & - & - & 6.89 & 12.92 & $10,331.82$ \\
20 & 55.71 & - & - & 6.05 & 6.81 & 7514.64 \\
\hline
\end{tabular}

It should be noted that these targets were only estimated for relevant variables for each DMU, i.e. in cases where the decision variables $\left(u_{r}\right.$ and $\left.v_{i}\right)$ weights had non-null values, thus generating Table 5 with the values found for input and output targets of each case in Table 6.

It should be noted that the BiO-MCDEA model indicated that for all DMUs, variable $v_{2}$ was not relevant, that is, the decision maker does not have to worry about setting goals for this variable.

Table 6 shows the targets for reducing inputs and increasing outputs, e.g. by comparing the data from the third row in Table 2 (original values) to those in the second row of Table 6 (targets). In order for DMU 1 to become efficient, the total hours should be reduced from $50.92 \%$ (170.49/334.8).100\%, installation hours should be reduced from (26.12/51.3).100\% hours of labor should be reduced from $50.92 \%=(18.33 / 36) .100 \%$, and the increase in production volume should be $196.37 \%=(20,615.13 / 10.498) .100 \%$.

It should be highlighted that, according to an expert's opinion of the planning area of chassis and presses of the company under study, in the future, the OME indicator can be adopted by the company, since combining the results of the BiO-MCDEA model with the OEE has a strong positive correlation.
However, under the company's current conditions, due to the targets of the DEA-CCR model being less aggressive and depending on a lower level of investments, these become more easily viable than those indicated by the OME.

Nevertheless, according to the consulted expert, setup hours are the most critical and the company under study is focused on reducing them in order to increase the machines availability and, consequently, increase the OEE. Therefore, the estimation of targets by the OME becomes rather useful at the moment, i.e. once targets are determined, one can manage the investment of resources more effectively, find the causes of inefficiencies to be dealt with and speed up the improvement process.

Figs. 5-9 illustrate a comparison of original value (Table 2) and recommended target value (Table 6), only for relevant inputs and output associated to all DMUs. For instance, in the sequence there are comments on the results illustrated in these figures for specific DMUs, noting that for the other DMUs it is possible to obtain similar suggestions.

Thus, analyzing Fig. 5, it is possible to recommend that DMU 2 should reduce the input $x_{1}$ (Total hours) from $256.1 \mathrm{~h}$ (see Table 2) to approximately $154.21 \mathrm{~h}$ (see Table 6). The company managers commented, in interviews, that these alterations can be easily implemented with the adequacy of the production line in product families that share similar machine configurations.

Observing Fig. 6, it is possible to recommend that DMU 2 should reduce the input $x_{3}$ (Setup hours) from $50.1 \mathrm{~h}$ (see Table 2) to approximately $30.17 \mathrm{~h}$ (see Table 6). One way to reduce Setup time is by Single-Minute Exchange of Die (SMED), which is a known methodology for reducing setup times in machines (Womack and Jones, 1994; Méndez and Rodríguez, 2016).

Observe that to use SMED methodology it is necessary an innovation effort, but in general the company is able to attend in a fast and effective way the occurrence of demand fluctuations, as well as it helps to eliminate waste and reduce lot sizes. SMED provides good solutions to the problem associated to how to prepare machines that are running a current product to run the next product.

Continuing to exemplify, by Fig. 7, it is recommended that DMU 2 should reduce input $x_{4}$ (WF) from 24 units (see Table 2) to approximately 14 units (see Table 6). This reduction can be done through training of the company's employees in the techniques of management of Lean Manufacturing and TPM (Womack and Jones, 1994; Ferko and Znidarsic, 2007).

Fig. 8 shows that the DMU 2 must maintain the input $x_{5}$ (Scrap) in 36 units (see Table 2), and the same applies to DMUS 1, 3, 4, 9, 10,

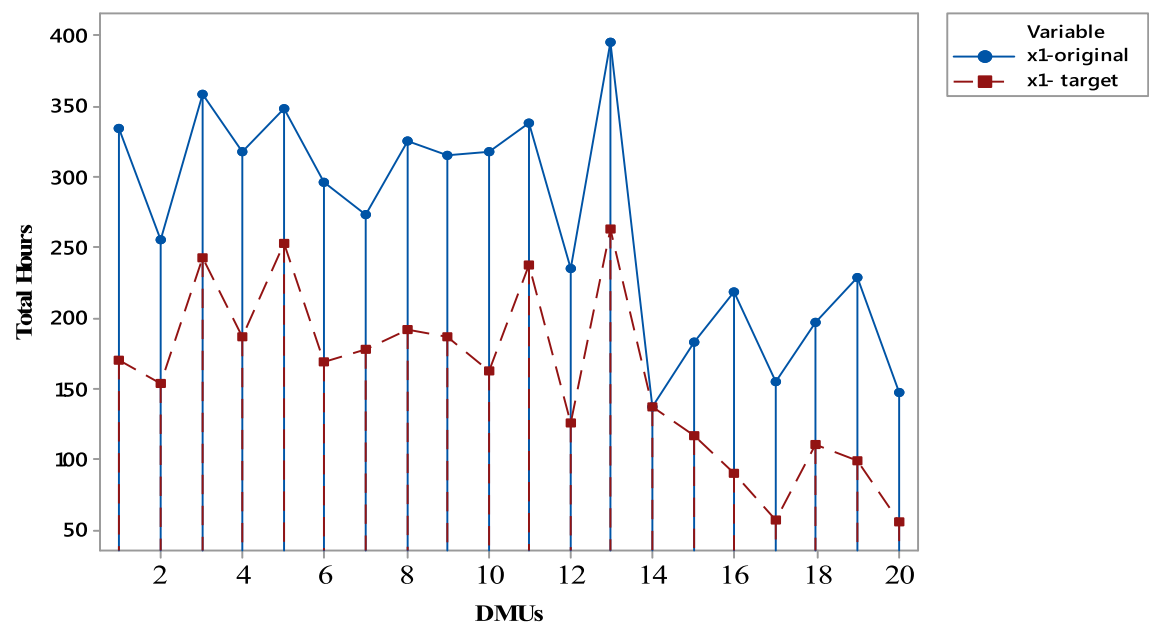

Fig. 5. Target values recommended by OME for reducing input $x_{1}$ for each DMU. Source: Minitab 17. 

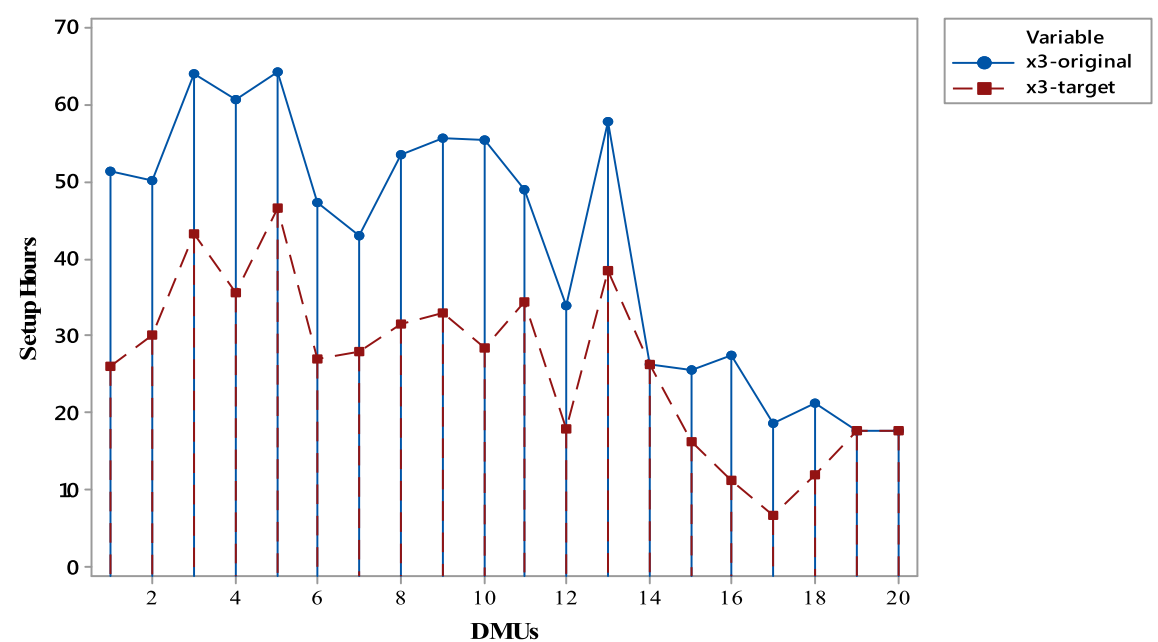

Fig. 6. Target values recommended by OME for reducing input $x_{3}$ for each DMU. Source: Minitab 17.
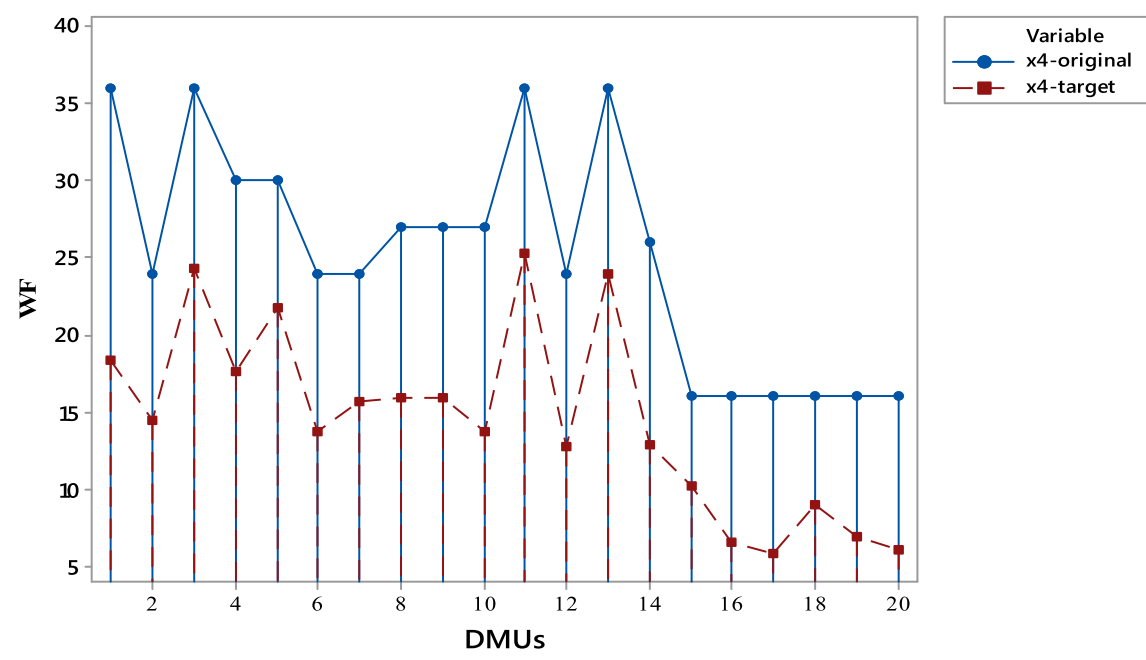

Fig. 7. Target values recommended by OME for reducing input $x_{4}$ for each DMU. Source: Minitab 17 .

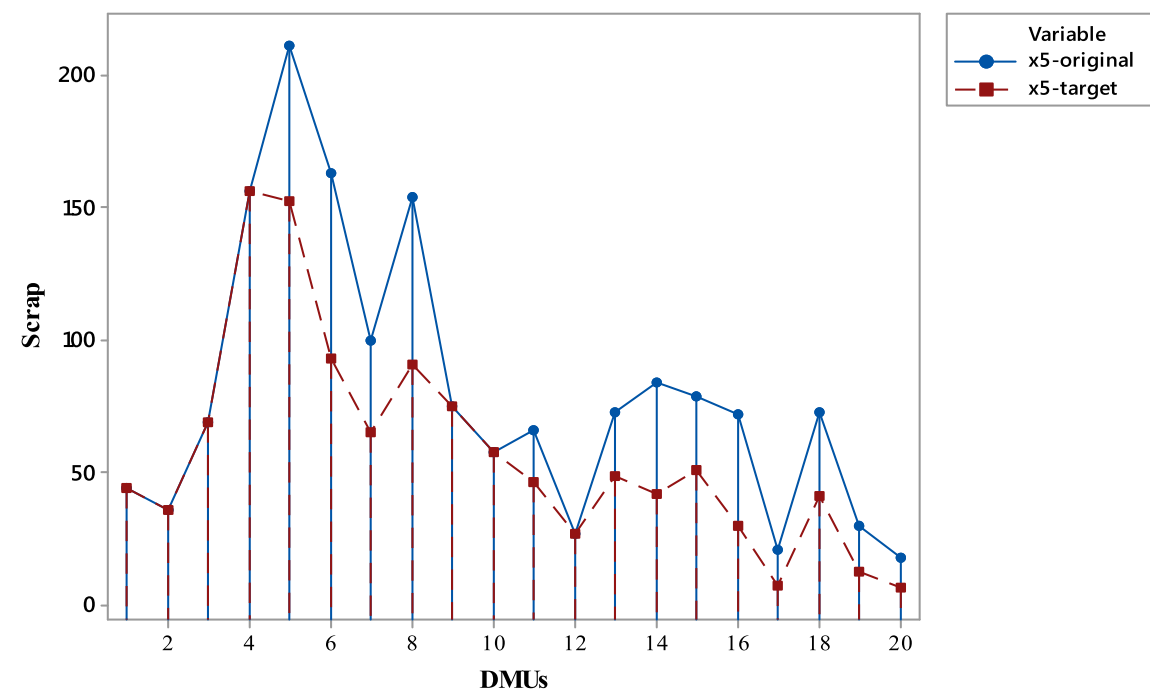

Fig. 8. Target values recommended by OME for reducing input $x_{5}$ for each DMU. Source: Minitab 17 . 


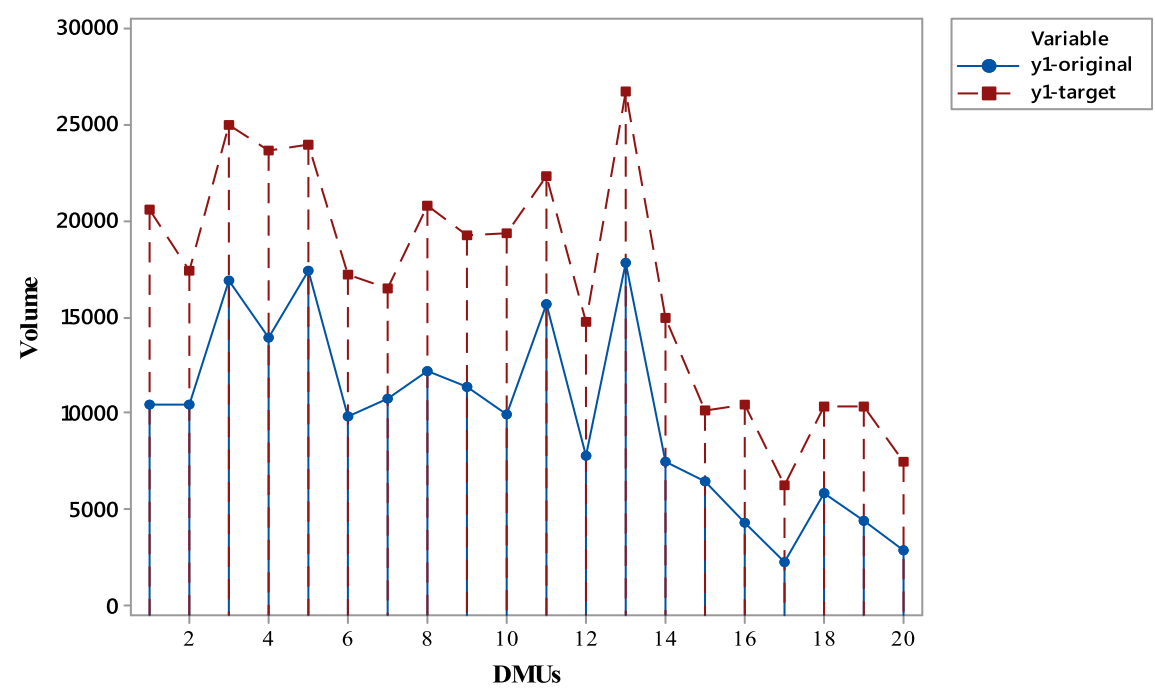

Fig. 9. Target values recommended by OME for increasing output $y_{1}$ for each DMU. Source: Minitab 17.

and 12; The DMU 5 should reduce $x_{5}$ from 211 units (see Table 2) to approximately 153 units (see Table 6). Note that Scrap reduction can be done by means of a study using Measurement Systems Analysis (MSA) (Asplund and Lin, 2016).

Finally, Fig. 9 shows that the DMU 2 should increase the output $y_{1}$ (Volume) from 10.46 units (see Table 2) to approximately 17.38 units (see Table 6). One of the ways to increase produced volume would be by expanding the customer base, and also by using advanced demand forecasting techniques (Meeran et al., 2017) in order to get more accurate values. It is worth mentioning that improving previous inputs will also lead to an improvement or increase in this output.

Continuing the analysis of the results obtained with the new OME indicator, in Fig. 10 are presented for each DMU, the percentage values of targets, established by OME indicator (Table 4), in relation to the original values of inputs and output (Table 2).

To exemplify how these values can be computed, in Table 7 are these calculations for DMU 1.
Observing Fig. 10, it is possible to see that DMU 17, which has the smallest OME value among all DMUs (see Table 4), presents the largest percentage values (comparing original and recommended target values) for reducing inputs, and for increasing output, which means it is more difficult to improve its performance or efficiency than of other DMUs. On the other hand, again from Fig. 9, DMU 5, that has the highest OME value among all DMUs (Table 4), presents the lowest percentage values (comparing original and recommended target values) for all input and output, meaning that to improve its performance or efficiency is easier.

\section{Conclusions and future research recommendations}

Based on the conducted analyses, it was possible to observe a contribution of the BiO-MCDEA model at calculating the efficiency of studied machines because, once combined with the OEE, which has been widely used in industries, has led to creation of a new and interesting indicator, the OME.

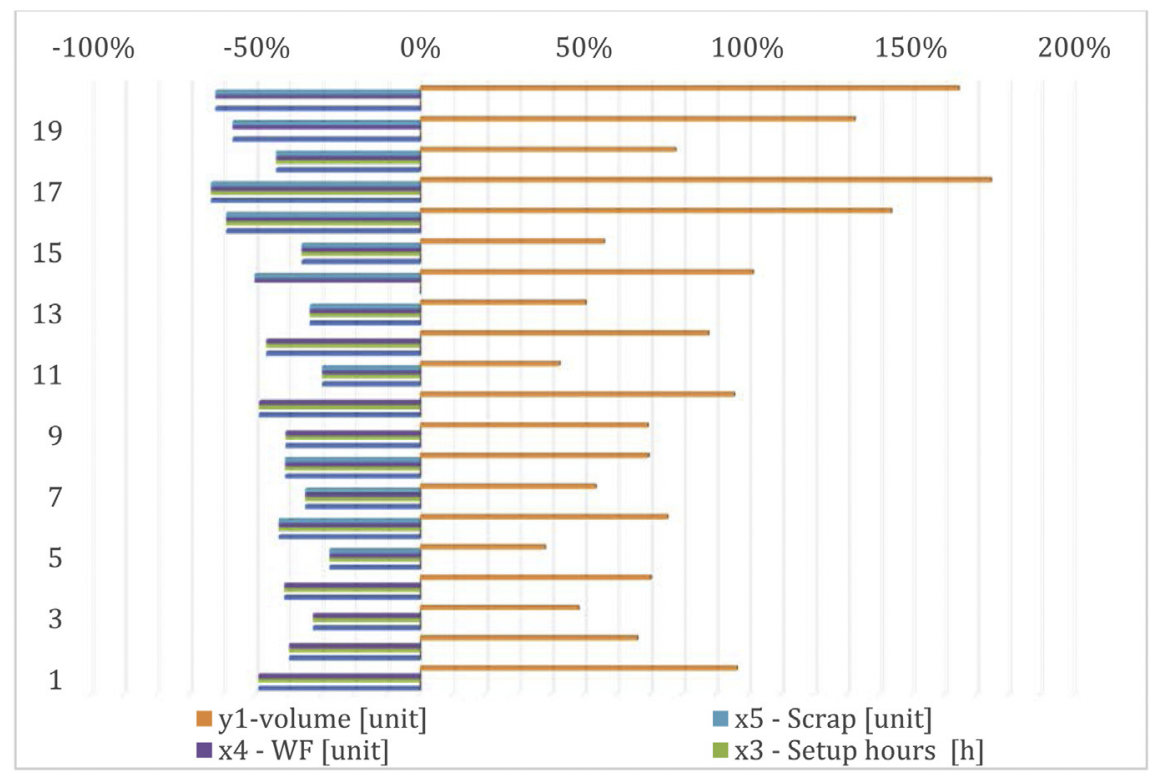

Fig. 10. Percentage values of targets, established by OME indicator, for each DMU. 
Table 7

Calculation of the percentage values of reduction of the original inputs and increase for the original output, recommended by the OME indicator, for the DMU 1.

\begin{tabular}{|c|c|c|c|c|c|c|}
\hline & \multicolumn{6}{|l|}{ DMU 1} \\
\hline & \multicolumn{5}{|l|}{ Inputs } & \multirow{2}{*}{$\frac{\text { Output }}{y 1}$} \\
\hline & $x_{1}$ & $x_{2}$ & $x_{3}$ & $x_{4}$ & $x_{5}$ & \\
\hline $\begin{array}{l}\text { (A) Target values } \\
\text { (Row 2, Table 4) }\end{array}$ & 170.49 & - & 26.12 & 18.33 & - & $20,615.13$ \\
\hline $\begin{array}{l}\text { (B) Original inputs and output values } \\
\text { (Row 2, Table 2) }\end{array}$ & 334.8 & 175.4 & 51.3 & 36 & 44 & 10,498 \\
\hline$(C)=(A / B-1)^{*} 100 \%$ & -49.08 & - & -49.08 & -49.08 & -49.08 & 96.37 \\
\hline
\end{tabular}

With the OME, it was possible to draw up new rankings of DMUs efficiency that assists in the company's decision-making process regarding investments focused at increased efficiency by identifying the most critical DMUs.

The selection of the relevant variables (input and output) by the OME indicator (See Table 5) shows to the decision maker which variables should be analyzed to increase the efficiency of the analyzed machines. It should be noted that the targets values suggested by the OME indicator (See Table 6) can be implemented by the company studied, thus showing the practical importance of this research.

In addition, the total time to optimize the models was approximately ten seconds, showing their feasibility for industrial problems requiring real-time solutions. The VBA modelling and the complete optimization results of the DEA-CCR and BiO-MCDEA models are, respectively, in the files Supplementary Data DEACCR and Supplementary Data BiO-MCDEA (see appendix A and appendix B).

As recommendations for further research, studies on the Fuzzy logic by analyzing data in an uncertainty context should be conducted, since factual information is fairly imprecise. In addition, it is proposed to conduct analyses with DEA models assuming variable return to scale (DEA-BCC model).

Lastly, it is worth mentioning that the results should not be generalized to all automotive industries yet, due to requiring further tests involving other areas, sectors and products, besides increasing the number of DMUs, inputs and outputs.

\section{Acknowledgements}

This research was partially supported by The National Council for Scientific and Technological Development (CNPq - 306214/ 2015-6), and Sao Paulo Research Foundation (FAPESP - 2015/127114; FAPESP- 2015/24560-0).

\section{Appendix A. Supplementary data}

Supplementary data related to this article can be found at http:// dx.doi.org/10.1016/j.jclepro.2017.04.147

\section{References}

Ahire, C.P., Relkar, A.S., 2012. Correlating failure mode effect analysis (FMEA) \& overall equipment effectiveness (OEE). Proc. Eng. 38, 3482-3486.

Aktin, T., Gergin, Z., 2011. Mathematical modelling of sustainable procurement strategies: three case studies. J. Clean. Prod. 113, 767-780.

Asplund, M., Lin, J., 2016. Evaluating the measurement capability of a wheel profile measurement system by using GR\&R. Meas 92, 19-27.

Banker, R.D., Charnes, A., Cooper, W.W., 1984. Some models for estimating technical and scale inefficiency in data envelopment analysis. Manag. Sci. 30, 1078-1092.

Banker, R.D., Charnes, A., Cooper, W.W., Swarts, J., Thomas, D.A., 1989. An introduction to data envelopment analysis with some of its models and their uses. Res. Gov. Non-Profit Acc. 5, 125-163.

Bertrand, J.W.M., Fransoo, J.C., 2002. Operations management research methodologies using quantitative modeling. I. J. Oper. Prod. Manag. 22, 241-264.

Blanchard, B.S., 1997. An enhanced approach for implementing total productive maintenance in the manufacturing environment. J. Qual. Maint. Eng. 3, 69-80.

Charnes, A., Cooper, W.W., Rhodes, E., 1978. Measuring the efficiency of decisionmaking units. Eur. J. Oper. Res. 2, 429-444.

Chen, L., Jia, G., 2017. Environmental efficiency analysis of China's regional industry: a data envelopment analysis (DEA) based approach. J. Clean. Prod. 142, 846-853.

Cook, W.D., Tone, K., Zhu, J., 2014. Data envelopment analysis: prior to choosing a model. Omega-Int. J. Manag. Sci. 44, 1-4.

Dotoli, M., Epicoco, N., Falagario, M., Sciancalepore, F., 2015. A cross-efficiency fuzzy Data Envelopment Analysis technique for performance evaluation of Decision Making Units under uncertainty. Comput 79, 103-114.

Eswaramurthi, K.G., Mohanram, P.V., 2013. Improvement of manufacturing performance measurement system and evaluation of overall resource effectiveness. Am. J. Appl. Sci. 10, 131-138.

Ferko, R., Znidarsic, A., 2007. Using OEE approach for improving manufacturing Performance. Infor. MIDEM 37, 105-111.

Ghasemi, M., Ignatius, J., Emrouznejad, A., 2014. A bi-objective weighted model for improving the discrimination power in MCDEA. Eur. J. Oper. Res. 233, 640-650.

Gupta, P., Vardhan, S., 2016. Optimizing OEE, productivity and production cost for improving sales volume in an automobile industry through TPM: a case study. I. J. Prod. Res. 54, 2979-2988.

Haghighi, S.M., Torabi, S.A., Ghasemi, R., 2016. An integrated approach for performance evaluation in sustainable supply chain networks (with a case study). J. Clean. Prod. 137, 579-597.

Hillier, F.S., Lieberman, G.J., 2010. Introduction to Operations Research, ninth ed. McGraw-Hill, New York.

Jasinski, D., Meredith, J., Kirwan, K., 2015. A comprehensive review of full cost accounting methods and their applicability to the automotive industry. J. Clean. Prod. 108, 1123-1139.

Li, X., Reeves, G.R., 1999. A multiple criteria approach to data envelopment analysis. E. J. Oper. Res. 115, 507-517.

Liu, S., 2008. A fuzzy DEA/AR approach to the selection of flexible manufacturing systems. Comput. Ind. Eng. 54, 66-76.

Maclean, H.L., Lave, L.B., 2003. Life cycle assessment of automobile/fuel options Environ. Sci. Technol. 37, 5445-5452.

Maxwell, D., van der Vorst, R., 2003. Developing sustainable products and services J. Clean. Prod. 11, 883-895.

Mayyas, A., Qattawi, A., Omar, M., Shan, D., 2012. Design for sustainability in automotive industry: a comprehensive review. Renew. Sustain. Energy Rev. 16, 1845-1862.

Meeran, S., Jahanbin, S., Goodwin, P., Neto, J.Q.F., 2017. When do changes in consumer preferences choice-based conjoint models unreliable? make forecasts from. Eur. J. Oper. Res. 258, 512-524.

Méndez, J.D.M., Rodríguez, R.S., 2016. Set-up reduction in an interconnection axle manufacturing cell using SMED. Int. J. Adv. Manuf. Technol. 84, 1907-1916.

Nakajima, S., 1989. An introduction to TPM. In: Nakajima, S. (Ed.), TPM Development Program: Implementing Total Productive Maintenance. Productivity Press, Massachusetts, pp. 1-26.

Nallusamy, S., 2016. Enhancement of productivity and efficiency of CNC machines in a small scale industry using total productive maintenance. I. J. Eng. Res. Afr. 25, 119-126.

Ohsato, S., Takahashi, M., 2015. Management efficiency in Japanese regional banks: a network DEA. Proc. Soc. Behav. Sci. 172, 511-518.

Ramón, J., Cristóbal, S.A., 2011. Multi criteria data envelopment analysis model to evaluate the efficiency of the Renewable Energy technologies. Renew. Energy 36, 2742-2746.

Schöggl, J.-P., Baumgartner, R.J., Hofer, D., 2017. Improving sustainability performance in early phases of product design: a checklist for sustainable product development tested in the automotive industry. J. Clean. Prod. 140, 1602-1617.

Tsarouhas, P.H., 2013. Evaluation of overall equipment effectiveness in the beverage industry: a case study. I. J. Prod. Res. 51, 515-523.

Womack, J.P., Jones, D.T., 1994. From lean production to the lean enterprise. Harv. Bull. Rev. 93-104.

Wudhikarn, R., 2012. Improving overall equipment cost loss adding cost of quality. I. J. Prod. Res. 50, 3434-3449.

Zhu, Q., Sarkis, J., Lai, K., 2007. Green supply chain management: pressures, practices and performance within the Chinese automobile industry. J. Clean. Prod. 15, 1041-1052. 